\title{
Simulation of the Dendrite Morphology and Microsegregation in Solidification of Al-Cu-Mg Aluminum Alloys
}

\author{
Rui Chen $\cdot$ Qing-Yan Xu $\cdot$ Bai-Cheng Liu
}

Received: 11 March 2014/Revised: 29 August 2014/Published online: 11 December 2014

(C) The Chinese Society for Metals and Springer-Verlag Berlin Heidelberg 2014

\begin{abstract}
Since most typical alloys in industrial applications are multicomponent with three or more components, and various CA models proposed in the past mainly focus on the binary alloys, a two-dimensional modified cellular automaton model allowing for the quantitatively predicting dendrite growth of multicomponent alloys in the low Péclet number regime is presented. The elimination of the mesh-induced anisotropy is achieved by adopting a modified virtual front tracking method. A new efficient method based on the lever rule is applied to calculate the solid fraction increment of the interfacial cells. The thermodynamic data such as liquidus temperature, the partition coefficients, and the slope of liquidus surface, needed for determining the dynamics of dendrite growth, are obtained by coupling with PanEngine. This model is applied to simulate the dendrite morphology and microsegregation of $\mathrm{Al}-\mathrm{Cu}-\mathrm{Mg}$ ternary alloy both for single and multidendrites growth. The simulated results demonstrate that the difference of the concentration distribution profiles ahead of the dendrite tip for each alloying element mainly results from the different partition coefficients and solute diffusion coefficients. Comparison with the prediction of analytical model is carried out and it reveals the correctness of the model. Consequently, the difference in interdendritic microsegregation behavior of different components is analyzed.
\end{abstract}

KEY WORDS: Cellular automaton; Multicomponent; Dendrite growth; Microsegregation

\section{Introduction}

Solidification of metals is a complex process and the microstructure developed throughout the solidification process directly determine the as-cast properties, and even has an influence on the final performance. Studying the formation mechanism of solidification microstructures and controlling for alloy designation have been widely concerned. Over the last decade, with the advance of computer technology, numerical modeling and simulation have been

Available online at http://link.springer.com/journal/40195

R. Chen · Q.-Y. Xu ( $\varangle)$ · B.-C. Liu

Key Laboratory for Advanced Materials Processing Technology,

Ministry of Education, School of Materials Science and

Engineering, Tsinghua University, Beijing 100084, China

e-mail: scjxqy@tsinghua.edu.cn widely used as a powerful tool to make a description of solidification microstructures [1-4], among which the dendrite morphologies along with the microsegregation are the predominant themes.

At present, various kinds of numerical models have been developed to simulate the evolution of the dendrite morphologies during solidification, and cellular automaton (CA) method, as an efficient computational approach for microstructural simulation with a high computational efficiency, can produce the similar results to those of the phase field (PF) method [5]. Therefore, CA method is rapidly emerging as a choice for simulating the dendrite formation during metal solidification. However, most of the CA models mainly focus on the binary systems. However, in the industrial applications, most if not all commercial alloys are multicomponent alloys with three or more components; hence, it would be significantly important to establish the models suitable for describing the microstructural formation of multicomponent 
alloys during solidification process. Jacot et al. [6] and Du et al. [7] developed a two-dimensional cellular automaton model coupled with thermodynamic data provided by Thermo-Calc to simulate the dendrite morphologies and microsegregation patterns during non-equilibrium solidification process for $\mathrm{Al}-\mathrm{Mg}-\mathrm{Si}$ and $\mathrm{Al}-\mathrm{Fe}-\mathrm{Mn}$ alloys. In their models, the thermodynamic equilibrium and uniform concentration for interfacial cells were assumed, and the concentration variation was converted into the variation of solid fraction by using lever rule method based on a complicated and time-consuming Newton-Raphson iterative algorithm. Zhu et al. $[8,9]$ extended their MCA model to the multicomponent alloy by coupling with phase equilibrium calculation engine PanEngine based on the strategy of data tabulation. However, in order to obtain the growth velocity of the interfacial cells, a hypothetical interface kinetic coefficient was prescribed in the model to connect the growth velocity with the local undercooling. Later, Michelic et al. [10] provide a comprehensive VFT model based on CA approach for multicomponent alloys. In this model, phase equilibrium locally at the solidification front was also assumed, and the interfacial equilibrium concentration was calculated based on a functional extrapolation toward the discontinuity at the interface, which was solved by multivariate non-linear Gauss-Newton regression. Furthermore, the dependence of the partition coefficients on the solute concentration and temperature was not implemented in the model, and the diffusion coefficients both for liquid and solid were taken as a constant. Using this model, the equiaxed and columnar dendrites of $\mathrm{Fe}-\mathrm{C}-\mathrm{Si}-\mathrm{Mn}-\mathrm{P}-\mathrm{S}$ system were simulated, and the capabilities of the model were illustrated by concentration profiles compared with Ohnaka microsegregation model.

In the current paper, a two-dimensional modified cellular automaton model suitable for the dendrite growth of multicomponent alloys in the low Péclet number regime is provided. The thermodynamic data needed for the dendrite growth are obtained through coupling with the thermodynamic software package-PanEngine [11]. This new method is used to calculate the solid fraction increment of interfacial cells, avoiding solving iterative algorithm. This model is applied to the microstructural simulation of Al$\mathrm{Cu}-\mathrm{Mg}$ ternary alloy both for single and multi-dendrite growths. Comparison with the analytical predictions for solid fraction variations is carried out. Consequently, the model is applied to investigate the microsegregation under different simulation conditions.

\section{Model Description and Numerical Algorithm}

In the present model, a two-dimensional rectangular calculation domain is uniformly divided into an orthogonal arrangement of square cells with the cell size of $\Delta x$ in Cartesian coordinate. Each of the spatial cells is possessed of several variables, such as temperature $(T)$, solute content $\left(w_{i}^{u}\right.$, which represents the concentration of element $i$ in phase $u$ (here $u=\mathrm{L}$ for liquid cell or $u=\mathrm{S}$ for solid cell)), solid fraction $\left(f_{\mathrm{S}}\right)$, etc. According to the solid fraction, the state of the cells can be identified as solid $\left(f_{\mathrm{S}}=1\right)$, liquid $\left(f_{\mathrm{S}}=0\right)$, and interface $\left(0<f_{\mathrm{S}}<1\right)$. Due to the fact that the local interface equilibrium composition $\left(w_{i}^{\mathrm{L} *}\right)$ of a growing cell is larger than its local actual liquid concentration $\left(w_{i}^{\mathrm{L}}\right)$ which is determined from mass transfer, in order to strive for equilibrium, part of the liquid in the cell will be solidified to reject the redundant solute which will diffuse to its neighboring liquid cells. In order to simulate the dendrite growth process, the governing equations used to calculate distribution of concentration and temperature, growth kinetics, solid fraction, and capturing rules will be described below.

\subsection{Thermal Field Distribution}

Prior to simulating the dendrites, thermal transport must be solved first. Since the calculation domain is on the scale of micrometer, it is reasonable to assume a uniform temperature among all the cells. According to the energy conservation condition, the temperature is calculated by [6]

$H(t)=\rho c_{p} \frac{\mathrm{d} T}{\mathrm{~d} t}-L \frac{\mathrm{d} \sum f_{\mathrm{S}}}{\mathrm{d} t}$,

where $H(t)$ is the heat extraction rate, $\rho$ is the density of molten melt, $c_{p}$ is specific heat, $L$ is the latent heat of fusion, and the second term on the right denotes the amount of latent heat released due to the solid fraction increment $\left(\mathrm{d} \sum f_{\mathrm{S}} / \mathrm{d} t\right.$ is the summation of the solid fraction increment of all interfacial cells during each time step).

\subsection{Solute Distribution Calculation}

Initially, the computational domain begins at a uniform composition, and zero-flux boundary condition is incorporated in the simulation domain. As the solidification proceeds, the growing cells reject excess solute to its neighboring liquid cells. To describe phase transformation of multicomponent system, the solute field of each alloy element needs to be calculated separately. Considering the fact that the mutual diffusion coefficients between the elements is much smaller compared with the self-diffusion coefficients [12], hence, the mutual diffusion process is neglected in the present model. Then the solute diffusion within the entire domain is calculated based on the following equation without considering natural and forced convection 
$\frac{\partial w_{i}^{u}}{\partial t}=\nabla \times\left(D_{i}^{u} \nabla w_{i}^{u}\right)+w_{\mathrm{L}}^{u}\left(1-k_{i}\right) \frac{\partial f_{\mathrm{S}}}{\partial t}$,

where $w$ is the composition with its superscript $u$ denoting solid or liquid and $i$ represents the alloying element, $D_{i}^{u}$ is the solute self-diffusion coefficient which is considered to be temperature dependent and $k_{i}$ is the non-constant equilibrium partition coefficient which is obtained through coupling PanEngine database. The solution for discontinuous property at the solid/liquid (S/L) interface is analyzed in detail in Ref. [13].

\subsection{Interface Growth Kinetics}

Assuming that the local thermodynamic equilibrium exists at the interface due to the influence of constitutional undercooling and curvature undercooling, the interface equilibrium temperature (i.e., the actual temperature in the domain calculated by Eq. (1)) is characterized by the following equation

$T(t)=T_{\mathrm{L}}^{\mathrm{liq}}\left(w_{i}^{\mathrm{L}}\right)-\Delta T_{\mathrm{C}}-\Delta T_{\mathrm{R}}$,

where $T_{\mathrm{L}}^{\mathrm{liq}}\left(w_{i}^{\mathrm{L}}\right)$ is the liquidus temperature read on the multicomponent phase diagram at a given set of concentrations $w_{i}^{\mathrm{L}} . \Delta T_{\mathrm{C}}$ and $\Delta T_{\mathrm{R}}$ are the constitutional and curvature undercooling, respectively. In order to consider the influence of different alloying elements on the constitutional undercooling, commonly, the method used is to superpose the effects of each alloying element. Therefore, the constitutional undercooling can be expressed as

$\Delta T_{\mathrm{C}}=\sum_{i} \frac{\partial T_{\mathrm{L}}^{\mathrm{liq}}\left(w_{i}^{\mathrm{L}}\right)}{\partial w_{i}^{\mathrm{L}}}\left(w_{i}^{\mathrm{L}}-w_{i}^{\mathrm{L} *}\right)$.

The term $\partial T_{\mathrm{L}}^{\mathrm{liq}}\left(w_{i}^{\mathrm{L}}\right) / \partial w_{i}^{\mathrm{L}}$ is the slope of the liquidus surface with respect to the solute element $i$ (i.e., $m_{i}^{\mathrm{L}}$ )at the composition $w_{i}^{\mathrm{L}}$ which is derived from Eq. (2), $w_{i}^{\mathrm{L} *}$ is the local equilibrium composition at the interface and its calculation is described in Sect. 2.4.

The curvature undercooling is calculated by the following expression:

$\Delta T_{\mathrm{R}}=\frac{\kappa}{S_{\mathrm{m}}}\left(\sigma_{\mathrm{S} / \mathrm{L}}(\varphi)+\frac{\partial^{2} \sigma_{\mathrm{S} / \mathrm{L}}(\varphi)}{\partial \varphi^{2}}\right)$,

where $\kappa$ denotes the curvature of $\mathrm{S} / \mathrm{L}$ interface, $S_{\mathrm{m}}$ is the entropy of melting, and $\sigma_{\mathrm{S} / \mathrm{L}}(\varphi)$ is the surface tension as a function of normal growth angle of the interface. The average counting method for curvature calculation suffers from a significant mesh dependent, resulting in the deviation of the curvature. Thus, the present model uses the following equation for the calculation of local interface curvature $\kappa$ of a cell with solid fraction $f_{\mathrm{S}}\left(0<f_{\mathrm{S}}<1\right)$ proposed by Belteran-Sanchez et al. [15]

$\kappa=\frac{\phi_{x x} \phi_{y}^{2}+\phi_{y y} \phi_{x}^{2}-2 \phi_{x} \phi_{y} \phi_{x y}}{\left(\phi_{x}^{2}+\phi_{y}^{2}\right)^{3 / 2}}$,

where the $\phi_{x}$ and $\phi_{y}$ represent the first order partial derivative of solid fraction $f_{\mathrm{S}}$ to $x$ and $y$ respectively, and $\phi_{x x}, \phi_{y y}$, and $\phi_{x y}$ are the second order partial derivatives.

The surface tension $\sigma_{\mathrm{S} / \mathrm{L}}(\varphi)$ is assumed to obey the following equation

$\sigma_{\mathrm{S} / \mathrm{L}}(\varphi)=\sigma_{\mathrm{S} / \mathrm{L}}^{0}(1+\varepsilon \cos [4(\varphi-\theta)])$,

where $\sigma_{\mathrm{S} / \mathrm{L}}^{0}$ is the surface energy, $\varepsilon$ denotes the anisotropy coefficient, and $\theta$ is the preferential crystallographic orientation with respect to the horizontal direction. The normal growth angle $\varphi$ can be calculated from the gradient of the solid fraction at $\mathrm{S} / \mathrm{L}$ interface cells by the following equation [16]

$\varphi=\left\{\begin{array}{ll}\cos ^{-1}\left(-\phi_{x} /\left(\phi_{x} \cdot \phi_{x}+\phi_{y} \cdot \phi_{y}\right)^{1 / 2}\right) & \phi_{x} \geq 0 \\ 2 \pi-\cos ^{-1}\left(-\phi_{x} /\left(\phi_{x} \cdot \phi_{x}+\phi_{y} \cdot \phi_{y}\right)^{1 / 2}\right) & \phi_{x}<0\end{array}\right.$.

Combining Eqs. (5) and (7), and employing the GibbsThomson coefficient $\Gamma$, the local curvature undercooling $\Delta T_{\mathrm{R}}$ can be expressed as

$$
\begin{aligned}
\Delta T_{\mathrm{R}} & =\frac{\sigma_{\mathrm{S} / \mathrm{L}}^{0}}{S_{\mathrm{m}}} \kappa[1-15 \varepsilon \cos (4(\varphi-\theta))] \\
& =\Gamma \kappa[1-15 \varepsilon \cos (4(\varphi-\theta))] .
\end{aligned}
$$

\subsection{Solid Fraction Increment Calculation}

Assuming that, on the scale of an interfacial cell, the concentration of each element is uniform, and the solid and liquid mixed well with a local equilibrium; therefore, the lever rule can be adopted to calculate the increment of solid fraction. The solute conservation of each solute element during each time step for interfacial cells yields the define equation for the solid fraction variation

$\Delta f_{\mathrm{S}}=\frac{w_{i}^{\mathrm{L} *}-w_{i}^{\mathrm{L}}}{w_{i}^{\mathrm{L} *}\left(1-k_{i}\right)}$.

For an alloy with $n$ kinds of alloying elements, Eqs. (3) and (11) forms a set of $n$ equations with $n$ unknowns ( $w_{i}^{\mathrm{L} *}$ and $\Delta f_{\mathrm{S}}$ ), and iterative algorithms were commonly used to solve the non-linear problem to get the values of the unknowns in the papers [6]. However, iterative algorithms usually have low computational efficiency with some calculation error. In the present model, the analytical solution expressions for each unknown are acquired using the Matlab software. Take $\mathrm{Al}-\mathrm{Cu}-\mathrm{Mg}$ ternary alloy as an 
example $(n=3)$, the calculated solid fraction according to $\mathrm{Cu}$ or $\mathrm{Mg}$ is assumed to be equal, thus

$\Delta f_{\mathrm{S}}=\frac{w_{\mathrm{Cu}}^{\mathrm{L} *}-w_{\mathrm{Cu}}^{\mathrm{L}}}{w_{\mathrm{Cu}}^{\mathrm{L} *}\left(1-k_{\mathrm{Cu}}\right)}=\frac{w_{\mathrm{Mg}}^{\mathrm{L} *}-w_{\mathrm{Mg}}^{\mathrm{L}}}{w_{\mathrm{Mg}}^{\mathrm{L} *}\left(1-k_{\mathrm{Mg}}\right)}$.

The analytical solution expressions for interfacial equilibrium concentrations $\left(w_{\mathrm{Cu}}^{\mathrm{L} *}, w_{\mathrm{Mg}}^{\mathrm{L} *}\right)$ and $\Delta f_{\mathrm{S}}$ can be directly obtained by a combination of Eqs. (3) and (11).

\subsection{Coupling Thermodynamic Data}

In the present model, the approach for microstructural simulation of multicomponent alloys is coupled with the thermodynamic and phase equilibrium calculation package-PanEngine. The thermodynamic data needed for the calculation are the liquidus temperature $T_{\mathrm{L}}^{\text {liq }}\left(w_{i}^{\mathrm{L}}\right)$, the partition coefficients $k_{i}$ and the slope of liquidus surface $m_{i}^{\mathrm{L}}$ as a function of liquid compositions $\left(w_{i}^{\mathrm{L}}\right)$. Due to the low computational efficiency and robustness problems for directly coupling with package-PanEngine, the optimized table-look-up technique is adopted to provide access to the phase diagram data in the model. Prior to simulation, a separate data file containing $w_{i}^{\mathrm{L}}, k_{i}, m_{i}^{\mathrm{L}}, T_{\mathrm{L}}^{\mathrm{liq}}\left(w_{i}^{\mathrm{L}}\right)$ is generated by PanEngine, and the relevant liquid concentrations are stored with a uniform composition of $0.01 \mathrm{wt} \%$. For each interfacial cell with a set of concentrations $w_{i}^{\mathrm{L}}$, the corresponding parameters $\left(k_{i}, m_{i}^{\mathrm{L}}, T_{\mathrm{L}}^{\mathrm{liq}}\left(w_{i}^{\mathrm{L}}\right)\right)$ can always be obtained.

\subsection{Description of Capturing Rules}

The two-dimensional sketch of virtual front-tracking algorithm for orthogonal grid previously proposed in Ref. [17] is adopted in the present model as shown in Fig. 1. Figure 1a illustrates the process of virtual reconstruction of sharp S/L interface. As can be seen, the liquid and solid cells are precisely separated by a layer of interfacial cells, and the arrows represent the normal vectors of the interfacial cells. The normal direction of each interfacial cell is determined by

$\hat{n}=-\nabla f_{S} /\left\|\nabla f_{S}\right\|=\cos \varphi i+\sin \varphi j$,

with $i$ and $j$ defining as the unit vectors along $x$-axis and $y$ axis, respectively. The length of the normal vector $L_{\varphi}$ is measured from the center of the interfacial cell along its normal direction and is proportional to the solid fraction $f_{\mathrm{S}}$

$L_{\varphi}=N \times f_{\mathrm{S}} \times \Delta x$,

where $N$ denotes the coefficient to ensure the reconstructed interface continuous $(N=1.5$ is adopted in the model). Thus, the coordinates of the normal vector with respect to the cell center can be calculated and then the interface envelope of the dendrite can be obtained by connecting the points once the solid fraction of all the interfacial cells has been calculated. At the end of every time step, the liquid cells adjacent are scanned to determine the newly captured cells. The capturing rules are illustrated in Fig. 1b. As the center coordinates of the liquid cell $(i, j+1)$ is located inside the quadrangle connected by the interfacial cell's center coordinates $(i, j)$, $(i+1, j)$ and their normal vector points $p_{1}, p_{2}$, the liquid cell $(i, j+1)$ is transformed into the interface state and start growing in the next time step.

\section{Simulation Results and Discussion}

To illustrate the abilities of the proposed model, solidification process of ternary $\mathrm{Al}-\mathrm{Cu}-\mathrm{Mg}$ alloys are simulated. The mesh size sensitivity has been analyzed in detail by Zhu and Stefanescu [13], and all the calculations in the
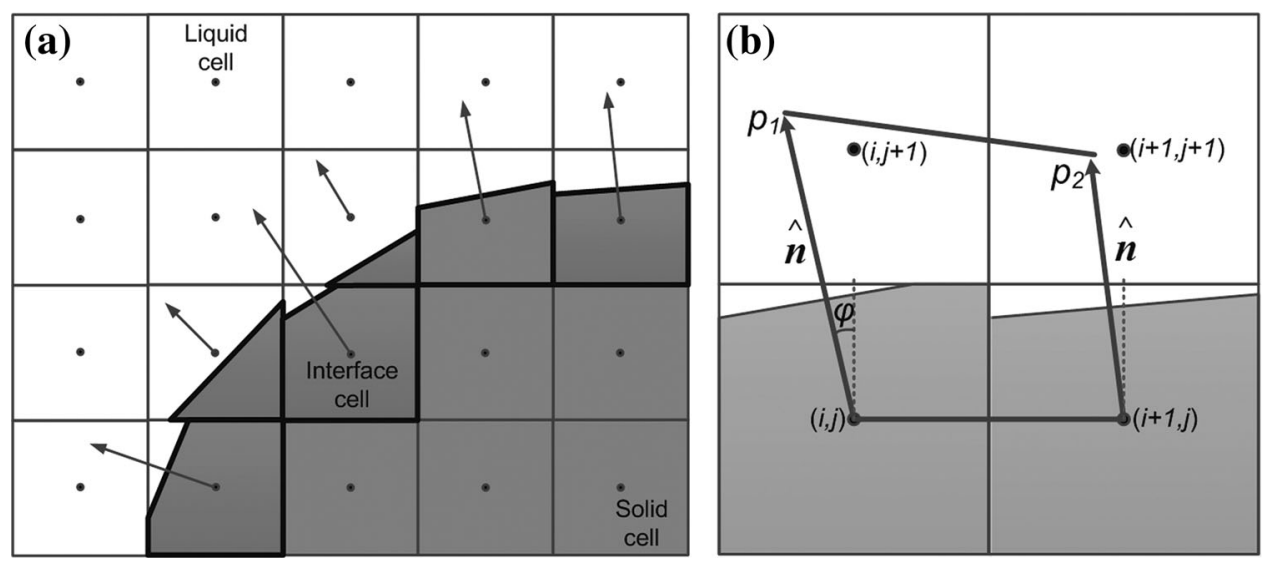

Fig. 1 a Schematic of the virtual front-tracking scheme, b illustration of its capturing rules for new interfacial cells 
following are performed with a mesh size $\Delta x=1 \mu \mathrm{m}$. The material properties are listed in Table 1.

\subsection{Single Dendrite Morphology and Solute Distribution}

The simulation was carried to investigate the dendrite morphology and the solute distribution. The computational domain used was $0.6 \mathrm{~mm} \times 0.6 \mathrm{~mm}$ and a single solid seed with initial composition $k_{i} w_{i}^{0}$ and preferential crystallographic orientation of $0^{\circ}$ with respect to the horizontal direction was set at the center of the domain. The constant cooling rate of $8 \mathrm{~K} / \mathrm{s}$ was imposed on the domain with an initial undercooling of $3 \mathrm{~K}$, and the simulated result is

Table 1 Properties of $\mathrm{Al}-\mathrm{Cu}-\mathrm{Mg}$ alloy used in the following simulations

\begin{tabular}{lll}
\hline Properties and symbol & $\mathrm{Al}-4 \mathrm{wt} \% \mathrm{Cu}-1 \mathrm{wt} \% \mathrm{Mg}$ & Ref. \\
\hline Initial compositions $w_{i}^{0}(\mathrm{wt} \%)$ & $w_{\mathrm{Cu}}^{0}=4.0 w_{\mathrm{Mg}}^{0}=1.0$ & \\
Liquidus temperature $T_{\mathrm{L}}^{\mathrm{liq}}\left(w_{i}^{0}\right)$ & 918.2 & \\
$\quad(\mathrm{~K})$ & & \\
Solute diffusion coefficient $D_{i}^{u}$ & $D_{\mathrm{Cu}}^{\mathrm{L}}=1.05 \times 10^{-7} e^{(-2856 / T)}$ & {$[18]$} \\
$\left(\mathrm{m}^{2} \cdot \mathrm{s}^{-1}\right)$ & $D_{\mathrm{Mg}}^{\mathrm{L}}=9.9 \times 10^{-5} e^{(-8610 / T)}$ & {$[18]$} \\
& $D_{\mathrm{Cu}}^{\mathrm{S}}=4.8 \times 10^{-5} e^{(-16069 / T)}$ & {$[18]$} \\
& $D_{\mathrm{Mg}}^{\mathrm{S}}=6.23 \times 10^{-4} e^{(-13813 / T)}$ & {$[18]$} \\
Gibbs-Thomson coefficient $\Gamma$ & $2.4 \times 10^{-7}$ & \\
$(\mathrm{~K} \cdot \mathrm{m})$ & & \\
Anisotropy coefficient $\varepsilon$ & 0.04 & \\
Latent heat of fusion & $9.5 \times 10^{8}$ \\
$L\left(\mathrm{~J} \mathrm{~m}^{-3} \mathrm{~K}^{-1}\right)$ & & \\
Density $\rho\left(\mathrm{kg} \mathrm{m}^{-3}\right)$ & 2,600 & \\
Specific heat $c_{\mathrm{p}}\left(\mathrm{J} \mathrm{kg}{ }^{-1} \mathrm{~K}^{-1}\right)$ & 1,070 \\
Time step $\delta t(\mathrm{~s})$ & $\Delta x^{2} / 4.5 \mathrm{max}\left(D_{\mathrm{Cu}}^{\mathrm{L}}, D_{\mathrm{Mg}}^{\mathrm{L}}\right)$ & \\
\hline
\end{tabular}

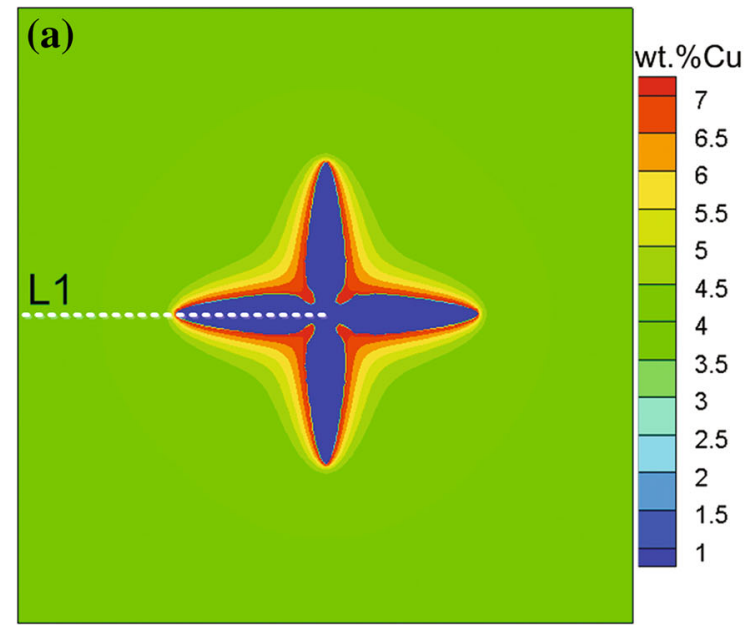

shown in Fig. 2. It can be seen that the dendrite arms can steadily develop along the crystallographic orientation and the dendrite morphology is presented as four-fold symmetry. From Fig. 2, it can be observed that the concentration both for $\mathrm{Cu}$ and $\mathrm{Mg}$ elements are piled up near the dendrite interface as a result of solute redistribution. Since the diffusivity of solute is much smaller than the dendrite growth velocity, the solute discharged from the newly solidified solid phase can not sufficiently diffuse to the bulk liquid.

In order to analyze the effects of partition coefficients $\left(k_{i}\right)$ and solute diffusion coefficients $\left(D_{i}^{u}\right)$ of different elements, the concentration profiles both for $\mathrm{Cu}$ and $\mathrm{Mg}$ along the horizontal dendrite arms from the dendrite center at different solidification times under the cooling rate of $8 \mathrm{~K} / \mathrm{s}$ are measured and plotted in Fig. 3. It can be seen that in the solid region, both $\mathrm{Cu}$ and $\mathrm{Mg}$ concentrations increase from the dendrite center to the dendrite tip which results from remarkable solute enrichment ahead of dendrite tip, and the increasing rate of $\mathrm{Mg}$ is larger than that of $\mathrm{Cu}$ which is mainly caused by a visibly higher partition coefficient (i.e., $k_{\mathrm{Mg}}=3 k_{\mathrm{Cu}}$ approximately). Note that the liquid concentration for $\mathrm{Cu}$ and $\mathrm{Mg}$ decays exponentially from the maximum value at dendrite tip to the bulk liquid. As solidification proceeds, the concentration at the dendrite tip increases while the thickness of diffusion layer $\Delta s$ declines. This can be accounted by the reason that as the solidification time extends, an increased undercooling appears in front of dendrite tip and gives rise to a higher growth rate. Therefore, less time is available for the accumulated solute to diffuse out, leading to higher solute concentration and narrower diffusion layer $\Delta s$. Furthermore, owing to the higher liquid diffusivity of $\mathrm{Mg}$ (i.e., $D_{\mathrm{Mg}}^{\mathrm{L}} \approx 2 D_{\mathrm{Cu}}^{\mathrm{L}}$ when the temperature exceeds $900 \mathrm{~K}$ ), the interfacial diffusion of Mg is more dispersed (see Fig. 2a, b), which can also be

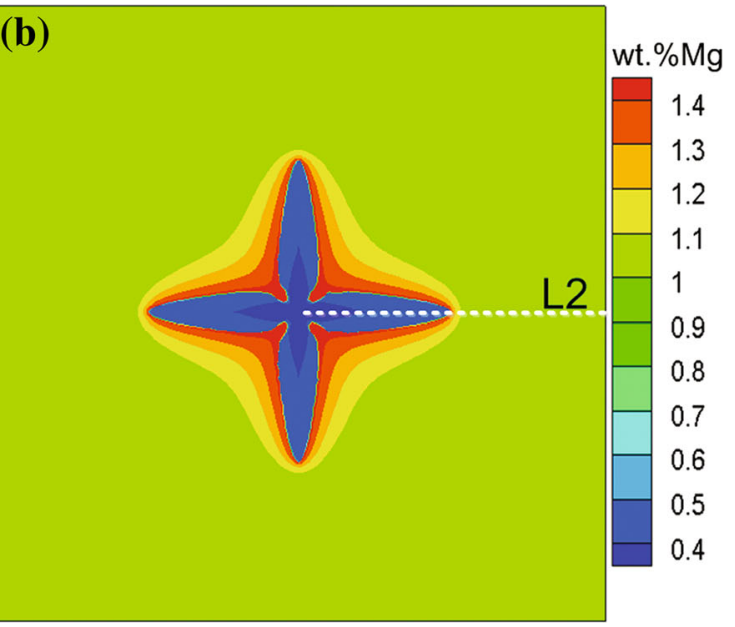

Fig. 2 Predicted dendrite morphologies and $\mathrm{Cu}$ concentration a, $\mathrm{Mg}$ concentration $\mathbf{b}$ fields for $\mathrm{Al}-4 \mathrm{wt} \% \mathrm{Cu}-1 \mathrm{wt} \% \mathrm{Mg}$ alloy 


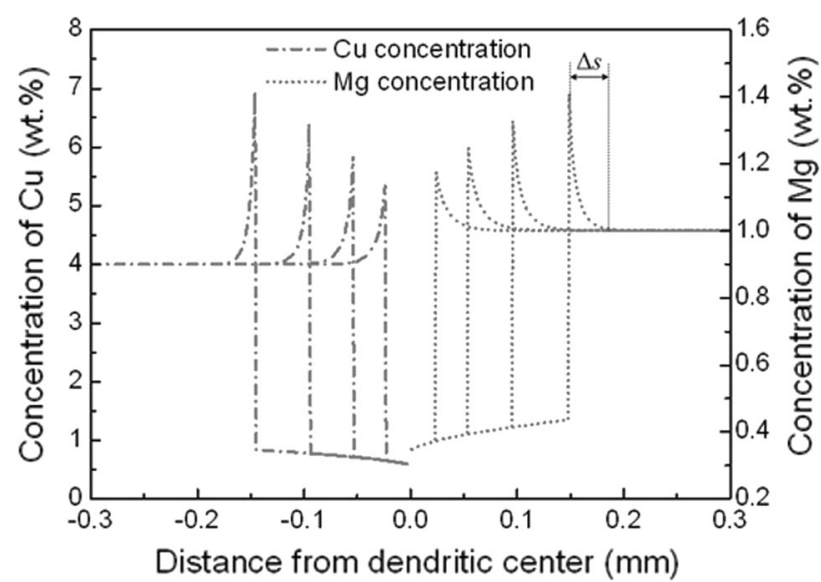

Fig. 3 Concentration profiles along the lines $\mathrm{L} 1$ and $\mathrm{L} 2$ indicated in Fig. 2a, b after solidification time of $0.15,0.3,0.45,0.6 \mathrm{~s}$. $\mathrm{L} 1 \mathrm{for} \mathrm{Cu}$ concentration and $\mathrm{L} 2$ for $\mathrm{Mg}$ concentration

demonstrated by the higher diffusion distance $\Delta s$ (see Fig. 3) for a given solidification time.

\subsection{Equiaxed Multi-dendrites Growth}

Since most industrial casting processes for aluminum alloys mainly involve equiaxed multi-dendrite growth and the majority of cooling conditions are no more than $20 \mathrm{~K} / \mathrm{s}$, this case is also simulated with the present model. Simulations were performed in a domain of $0.6 \mathrm{~mm} \times 0.6 \mathrm{~mm}$ with different heat extraction rates and initially 25 nuclei with random preferential growth orientations were randomly distributed in the domain. In consideration of the importance of solid diffusion in determining the solidification kinetics in multicomponent systems, the influence of the solid diffusion on microsegregation and secondary phase amounts under different cooling conditions is investigated by present model.

Prior to analyzing the simulated microstructure, a verification of the model was achieved by comparing with analytical model, and the results are shown in Fig. 4 considering the variation of solid fraction as a function of temperature. The label PM in Fig. 4 corresponds to the present model. The three simulations under different heat extraction rates were carried out under the condition of no diffusion in the solid both for $\mathrm{Cu}$ and $\mathrm{Mg}$ elements (i.e., $D_{\mathrm{Mg}}^{\mathrm{S}}=0, D_{\mathrm{Cu}}^{\mathrm{S}}=0$ ). As can be seen in Fig. 4 , under equilibrium condition (i.e., Lever rule), the alloy completely solidified as the primary phase without eutectic formation, while the predicted results by Scheil model and present model reveal that eutectic reaction would occur at the end of solidification. At the initial transition period, the predictions by the present model are lower compared with Scheil model, whereas the difference decreases as the heat extraction rate is reduced. This difference can be explained

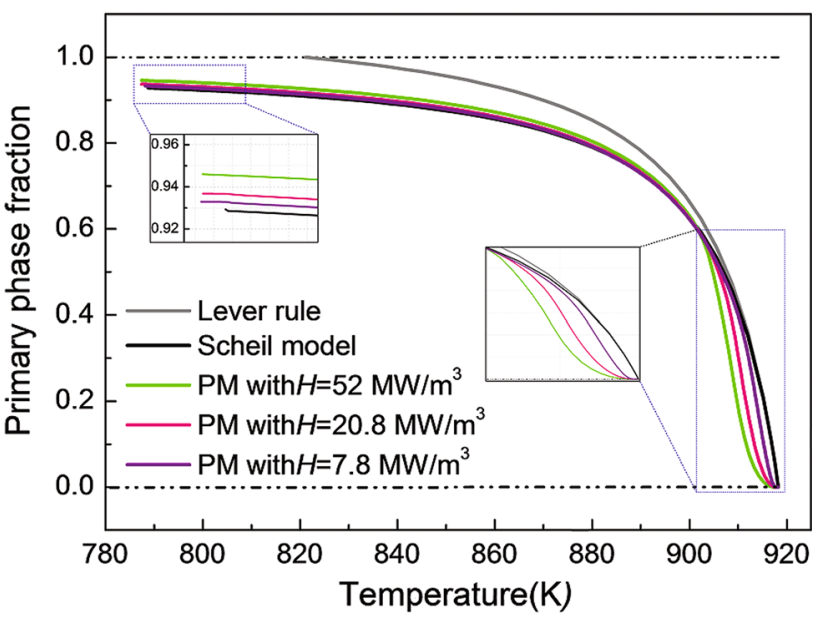

Fig. 4 The solid fraction evolution of primary phase with the temperature for $\mathrm{Al}-4 \mathrm{wt} \% \mathrm{Cu}-1 \mathrm{wt} \% \mathrm{Mg}$ alloy calculated by Lever rule, Scheil model as well as the present model with different heat extraction rates

by the fact that the uniform concentration of liquid in Scheil model is assumed while in the present model, the distribution of the composition in the liquid is actually nonuniform (see Fig. 2), which results in higher prediction value of $w_{i}^{\mathrm{L}}$, thus causing the less increment of solid fraction predicted by present model (see Eq. (10)). At the final stage of solidification, the predicted fraction of the primary phase is higher than that of Scheil model and the higher heat extraction rate leads to a higher deviation. The phenomenon also can be explained by the fact of nonuniform solute distribution in the liquid. From the analysis above, it reveals that the calculated data will coincide very well with the Scheil model if the cooling rate is quite small (low cooling rates needs too long calculation time for the present model).

Figure 5 displays the simulated final dendrite morphologies and the concentration fields of $\mathrm{Cu}$ and $\mathrm{Mg}$ for a heat extraction rate $H=52 \mathrm{MW} / \mathrm{m}^{3}$ (i.e., equivalent to a cooling rate of $20 \mathrm{~K} / \mathrm{s}$ before solidification). In Fig. 5a, b, the solid diffusion coefficient $D_{i}^{\mathrm{S}}=0$. It can be clearly seen from Fig. 5 that well-developed secondary dendrite arm is achieved in the region with less grain density which can demonstrated that the grain density can influence the final dendrite morphologies [7]. With the coarsening and coalescence of primary and secondary dendrite arms, the liquid among interdendritic regions and grain boundaries are separated into discrete liquid droplets in which the solute is substantially enriched and eutectic reaction would take place in these regions with further solidification.

Since the diffusivity in the solid is several orders of magnitude smaller than that in the liquid, the composition distribution in the solid is non-uniform with the regions near the liquid occupying a higher concentration as can be 

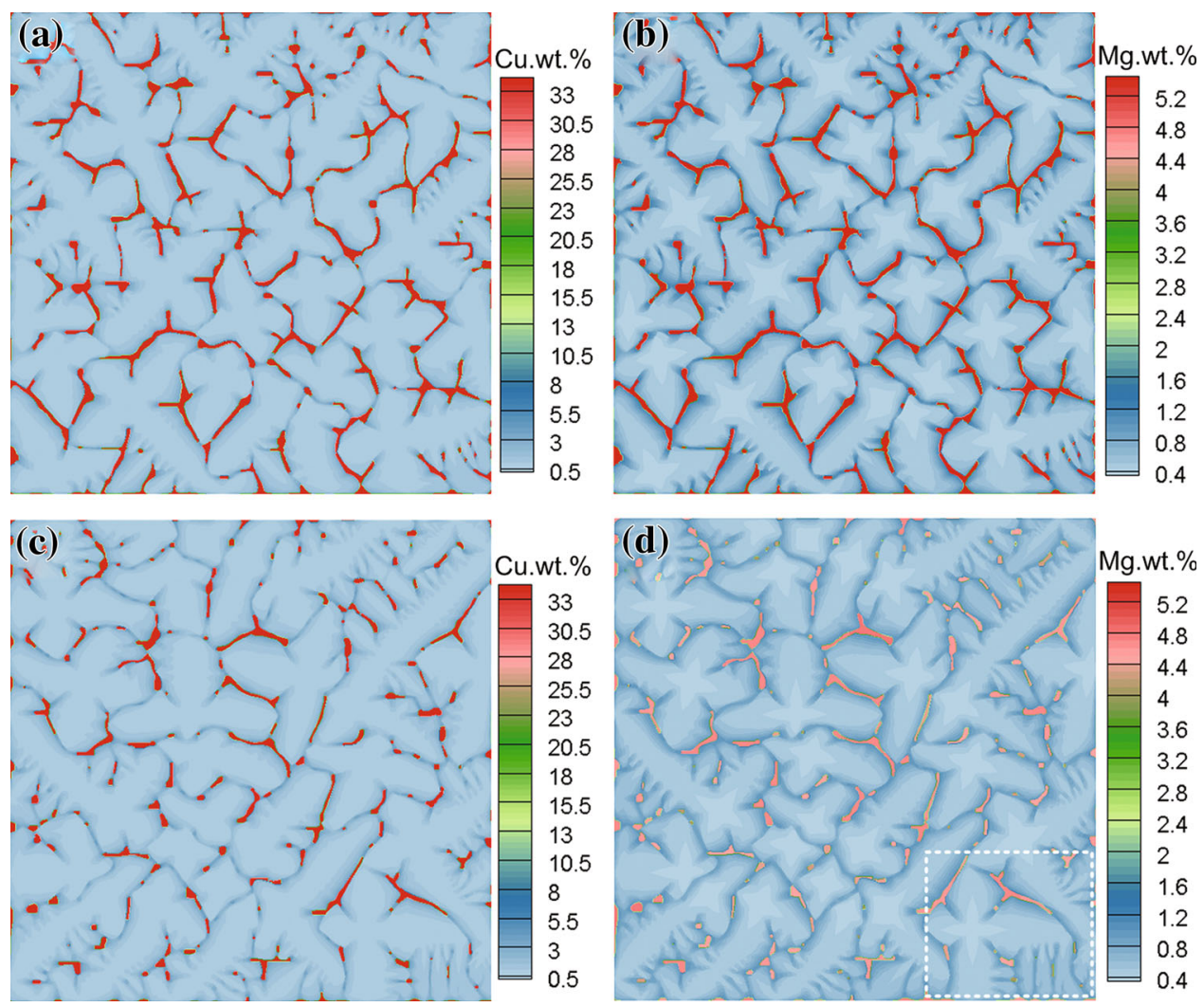

Fig. 5 Simulated dendrite morphologies and the solute fields of $\mathrm{Cu} \mathbf{a}, \mathbf{c}, \mathrm{Mg} \mathrm{b}, \mathbf{d}$ for $\mathrm{Al}-4 \mathrm{wt} \% \mathrm{Cu}-1 \mathrm{wt} \% \mathrm{Mg}$ alloy with a heat extraction rate $H=52 \mathrm{MW} / \mathrm{m}^{3}: \mathbf{a}, \mathbf{b} D_{\mathrm{Mg}}^{\mathrm{S}}=0, D_{\mathrm{Cu}}^{\mathrm{S}}=0, \mathbf{c}, \mathbf{d} D_{\mathrm{Mg}}^{\mathrm{S}} \neq 0, D_{\mathrm{Cu}}^{\mathrm{S}} \neq 0$. The red color region in the images represents the eutectic region

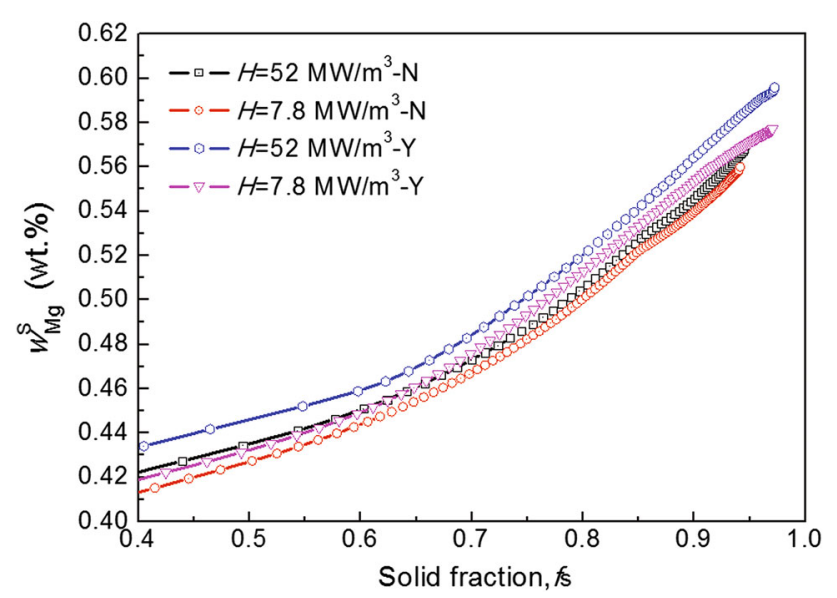

Fig. 6 Simulated average concentration of $\mathrm{Mg}$ in the solid as a function of solid fraction under different cooling conditions. $N$ in the figure represents no solid diffusion taking into consideration while $Y$ represents with solid diffusion

seen in Fig. 5. Furthermore, because of the higher partition coefficient, the Mg element is less well distributed in the primary phase compared with $\mathrm{Cu}$ element. In order to quantitatively show the effect of the solid diffusion on the microsegregation, the average solid concentration of $\mathrm{Mg}$ element as a function of solid fraction is illustrated in Fig. 6. It can be seen that solid diffusion can increase the average solute concentration in the solid and reduce that in the liquid, ultimately leading to a decrease of the eutectic amounts. For a heat extraction rate $H=52 \mathrm{MW} / \mathrm{m}^{3}$, the eutectic fraction under consideration of the solid diffusion is $3 \%$ while it is $5.5 \%$ for no solid diffusion as shown in Fig. 5. The remarkable differences both for eutectic amounts and concentration field emphasize the importance of taking solid diffusion into consideration in microstructural simulation.

\subsection{Microsegregation Analysis}

In this section, the differences in interdendritic segregation of $\mathrm{Cu}$ and $\mathrm{Mg}$ element are investigated. Due to the high diffusivity in the liquid, solute in the remaining interdendritic liquid is relatively uniform as is shown in Fig. 5. However, by comparing the results in Fig. 5b, d, an interesting phenomenon can be observed under $D_{i}^{\mathrm{S}} \neq 0$ condition, the liquid concentration of $\mathrm{Mg}$ is relative nonuniform (see Fig. 5d). The growth process in the region of the dashed line square indicated in Fig. 5 is shown in Fig. 7. It can be found that in the small regions formed as a 

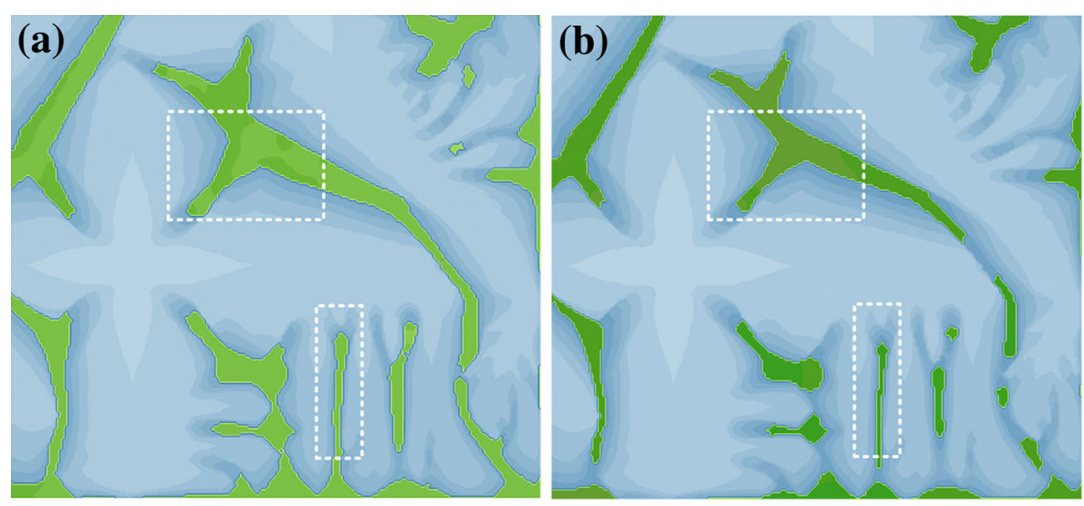

\section{Mg.wt.\%}
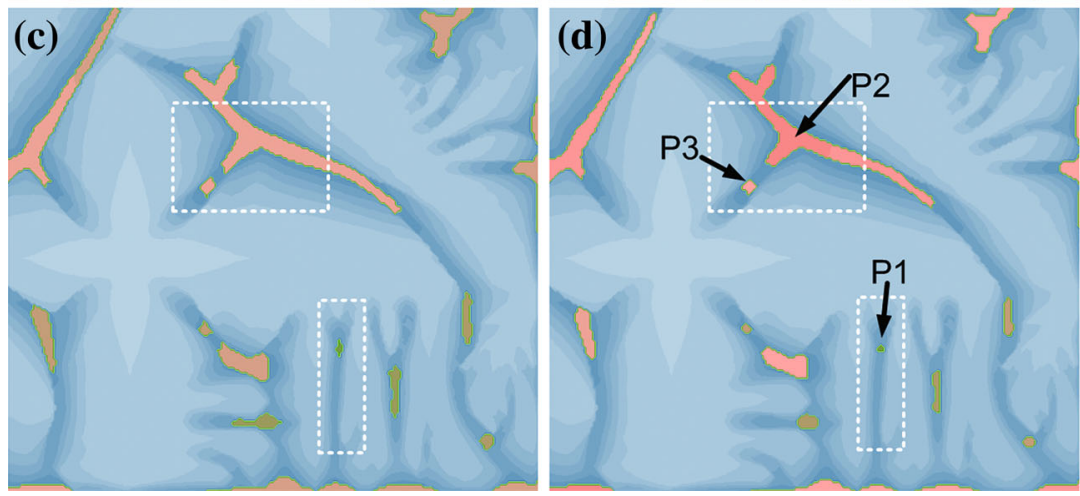

5.2

4.8

4.4

4

3.6

3.2

2.8

2.4

2

1.6

1.2

0.8

0.4

Fig. 7 Magnification of the region indicated by the dashed line in Fig. 6d: a, b, c, $\mathbf{d}$ illustrates the dendrite morphologies and concentration fields of $\mathrm{Mg}$ at solidification time of $2.5,3.2,5.5,6.1 \mathrm{~s}$, respectively
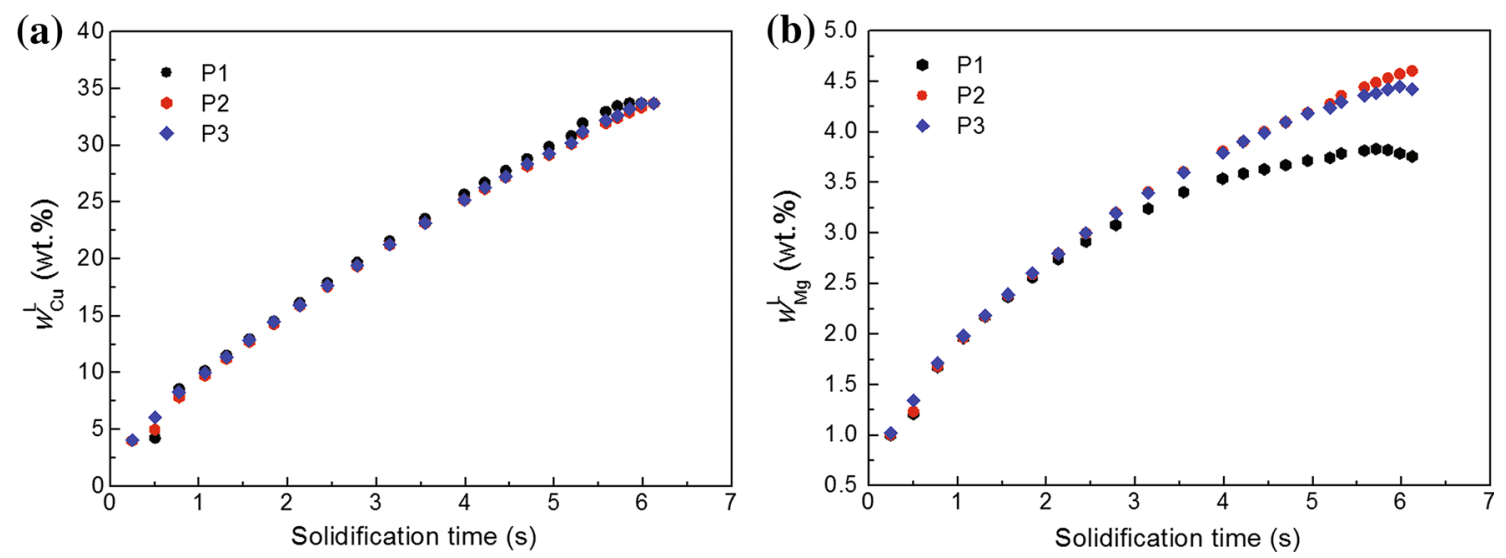

Fig. 8 Illustration of the differences of solute enrichment of $\mathrm{Cu} \mathbf{a}, \mathrm{Mg} \mathbf{b}$ elements in the interdendritic regions as a function of solidification time. Positions of P1, P2, P3 points are indicated in Fig. 7d

result of coarsening and coalescence of secondary and tertiary dendrite arms, the $\mathrm{Mg}$ solute concentration is smaller than that in the grain boundaries. This mainly attributes to the active diffusion from the liquid to the solid because those small regions occupy a larger area of S/L interface per unit volume [19]. In order to further demonstrate the influence of the dendrite coarsening on the interdendritic microsegregation, as shown in Fig. 8, three points marked P1, P2, P3 in Fig. 7d are chosen and the concentration variation histories of $\mathrm{Mg}$ and $\mathrm{Cu}$ are illustrated. P1 and P2 are at the intersection region of the dendrite arms while P3 locates at the grain boundary. The results in Fig. 8a show that the concentrations of $\mathrm{Cu}$ at different positions have neglectable difference during the whole solidification process which reveals that the distribution of $\mathrm{Cu}$ element in the liquid is uniform independent of the dendrite morphologies. The relative smaller partition coefficient (i.e., $k_{\mathrm{Mg}} \approx 2 k_{\mathrm{Cu}}$ ) and lower solid diffusivity 
(i.e., $D_{\mathrm{Mg}}^{\mathrm{S}} \approx 2 D_{\mathrm{Cu}}^{\mathrm{S}}$ ) of $\mathrm{Cu}$ at the end of solidification can account for this phenomenon. From Fig. 8b, it can be seen that before the solidification time of $2.5 \mathrm{~s}$ (see Fig. 7a), the concentration evolution of $\mathrm{Mg}$ at different points corresponds very well. When the solidification time $t=3.2 \mathrm{~s}$, the tertiary dendrite arms nearby coalesce (see Fig. 7b), and a larger area of $\mathrm{S} / \mathrm{L}$ interface per unit volume produced which results in the enhanced effect of diffusion from liquid to solid [20], leading to a less concentration increment at P1 point. With the further increase of the solidification time to $5.5 \mathrm{~s}$, the concentration in the small region of P3 separated from P2 also appears a lower increasing rate. When the time increases to $6.1 \mathrm{~s}$, the concentrations of P1 and P3 decrease slightly. Therefore, it can be concluded from this analysis that dendrite coarsening at the final solidification stage can enhance diffusion behavior from liquid to solid, thus influencing the non-uniformity of the concentration in the remaining liquid. According to the discussion of Kraft [21], the influence of coarsening on solute redistribution is significant when the partition coefficient exceeds 0.2. This can also explain the different behavior in solute redistribution of $\mathrm{Cu}\left(k_{\mathrm{Cu}}<0.2\right)$ and $\mathrm{Mg}$ $\left(k_{\mathrm{Cu}}>0.2\right)$ as indicated in Fig. 8.

\section{Conclusions}

In the present paper, a novel two-dimensional modified cellular automaton model coupled with thermodynamic package-PanEngine for quantitatively predicting the dendrite growth of multicomponent alloys in the low Péclet number regime is developed. The mesh-induced anisotropy is eliminated by adopting a modified virtual front tracking method (VFT). The growth kinetics of S/L interface cells are determined from the difference between the local interface equilibrium composition $\left(w_{i}^{\mathrm{L} *}\right)$ and local actual liquid composition $\left(w_{i}^{\mathrm{L}}\right)$, and the solid fraction increment calculation is achieved by solving local lever rule equation based on a new and efficient method.

The ternary $\mathrm{Al}-\mathrm{Cu}-\mathrm{Mg}$ alloy is applied to demonstrate the capabilities of the model. The difference in the concentration profiles of $\mathrm{Cu}$ and $\mathrm{Mg}$ ahead of the dendrite tip clarifies that solute distribution both in the solid and liquid is significantly controlled by the partition coefficient and solute diffusivity. Comparison with the predictions of analytical model for the solid fraction evolution as a function of temperature reveals the correctness of the model. Through analysis of the concentration variation both in the liquid and solid, it was found that solid diffusion significantly influences the microsegregation and eutectic amounts. Furthermore, the difference in interdendritic enrichment of each alloy element is analyzed and the influence of enhanced solid diffusion due to dendrite coarsening is outlined.

Acknowledgments This work was financially supported by the National Basic Research Program of China (No. 2011CB706801), the National Natural Science Foundation of China (Nos. 51171089 and 51374137) and the National Science and Technology Major Project of the Ministry of Science and Technology of China (No. 2012ZX04012-011).

\section{References}

[1] L. Wei, X. Lin, M. Wang, W.D. Huang, Phys. B 407, 2471 (2012)

[2] M. Asle Zaeem, H. Yin, S.D. Felicelli, Appl. Math. Model. 37, 3495 (2013)

[3] U. Hecht, L. Granasy, T. Pusztai, Mater. Sci. Eng. R 46, 1 (2004)

[4] W. Tan, N.S. Bailey, Y.C. Shin, Comput. Mater. Sci. 50, 2573 (2011)

[5] A. Choudhury, K. Reuther, E. Wesner, A. August, B. Nestler, Comput. Mater. Sci. 55, 263 (2012)

[6] A. Jacot, M. Rappaz, Acta Mater. 20, 1909 (2002)

[7] Q. Du, A. Jacot, Acta Mater. 53, 3479 (2005)

[8] M.F. Zhu, W. Cao, S.L. Chen, C.P. Hong, Y.A. Chang, J. Phase Equilib. Diffus. 28, 130 (2007)

[9] T. Dai, M.F. Zhu, S.L. Chen, W.S. Cao, C.P. Hong, Acta Metall. Sin. 44, 1175 (2008). (in Chinese)

[10] S.C. Michelic, J.M. Thuswaldner, C. Bernhard, Acta Mater. 58, 2738 (2010)

[11] W. Cao, S. Chen, F. Zhang, K. Wu, Y. Yang, Y.A. Chang, R. Schmid-Fetzer, W.A. Oates, Calphad 33, 328 (2009)

[12] R.J. Zhang, T. Jing, W.Q. Jie, B.C. Liu, Scr. Mater. 48, 689 (2003)

[13] M.F. Zhu, D.M. Stefanescu, Acta Mater. 55, 1741 (2007)

[14] L. Nastac, Acta Mater. 47, 4253 (1999)

[15] L.B. Sanches, D.M. Stefanescu, Metall. Mater. Trans. A 34, 367 (2003)

[16] M. Asle Zaeem, H. Yin, S.D. Felicelli, J. Mater. Sci. Technol. 28, 137 (2012)

[17] L.B. Sanches, D.M. Stefanescu, Metall. Mater. Trans. A 35 , $2471(2004)$

[18] F.Y. Xie, T. Kraft, Y. Zuo, C.H. Moon, Y.A. Chang, Acta Mater. 47, 489 (1999)

[19] Q. Du, D.G. Eskin, A. Jacot, L. Katgerman, Acta Mater. 55, 1523 (2007)

[20] J.J. Li, J.C. Wang, G.C. Yang, Chin. Phys. B 17, 3516 (2008)

[21] T. Kraft, Y.A. Chang, Metall. Mater. Trans. A 29, 2447 (1998) 